Nathalie Cals

Gérald Devuyst

Nazire Afsar

Theodore Karapanayiotides

Julien Bogousslavsky

\section{Pure superficial posterior cerebral artery territory infarction in The Lausanne Stroke Registry}

Abstract Objective To determine the patterns of clinical presentation, lesion topography, and etiology in patients with ischemic stroke limited to the superficial territory of the posterior cerebral artery (s-PCA). Methods In the Lausanne Stroke Registry (LSR, 1983-1998), we determined the patterns of clinical presentation,

Received: 31 July 2001

Received in revised form:

23 November 2001

Accepted: 4 December 2001

N. Cals, MD • G. Devuyst, MD •

N. Afsar, MD · T. Karapanayiotides, MD .

J. Bogousslavsky, MD

Department of Neurology

CHUV BH 07

Rue du Bugnon, 46

1011 Lausanne, Switzerland

Tel.: + 41-21/3 14-12 25

Fax: + 41-21/3 14-1290

E-Mail: gerald.devuyst@chuv.hospvd.ch lesion topography and mechanisms of stroke, among 117 patients with s-PCA infarction (s-PCAI) on brain imaging. Results s-PCAIs accounted for $30.5 \%$ of all PCA territory ischemic strokes. The presumed etiology was embolism in $64(54.5 \%)$ patients [cardiac in 51 $(43.5 \%)$ and arterial in $13(11 \%)]$, indeterminate in $38(32 \%)$, PCA atherothrombosis in $4(3.4 \%)$, migraine in $4(3.4 \%)$, other rare causes in $4(3.4 \%)$, and multiple potential sources of embolism in 3 $(2.5 \%)$. The clinical findings were hemianopsia in $78(67 \%)$, quadrantanopsia in $26(22 \%)$, and bilateral visual field defects in $8(7 \%)$. Motor, sensory, or sensorimotor deficits were detected in $14(12 \%)$, $8(6.8 \%)$, or $8(6.8 \%)$ patients, respectively. Neuropsychological dysfunction included memory impairment in 20 (17.5\%; with left $[L]$, right $[R]$, or bilateral [B] lesions in 15, 2, or 3 patients, respectively), dysphasia in 17 (14.5\%; L/B: 14/3), dyslexia with dysgraphia in $5(4 \%$; L/B: $4 / 1)$, dyslexia without dysgraphia in $10(8.5 \%$; L/B: $8 / 2)$, hallucinations in $12(10 \%$; L/R/B: 5/5/2), visual neglect in 11 (9.5\%; L/R: $2 / 9)$, visual agnosia in 10 (8.5\%; L/B: 7/3), prosopagnosia in $7(6 \% ; \mathrm{R} / \mathrm{B}: 4 / 3)$, and color dysnomia in $6(5 \%$; $: 6)$. Conclusions s-PCAIs are uncommon, representing less than a third of all PCA infarctions. Although embolism is the main cause in $60 \%$ of patients, identification of the emboli source is often not possible. In $1 / 3$ of cases, the stroke mechanism cannot be determined. Neuropsychological deficits are frequent if systematically searched for.

Key words stroke posterior cerebral artery $\cdot$ Lausanne Stroke Registry

\section{Introduction}

Posterior cerebral artery territory infarcts (PCAIs) represent $5-10 \%$ of all strokes in the general population [5]. Isolated superficial territory of the posterior cerebral artery infarctions (s-PCAIs), including combinations of the areas supplied by the calcarine, temporo-occipital, parieto-occipital, and temporal arteries, are relatively uncommon, accounting for approximately one-third of all PCAIs [23]. Since the advent of non-invasive methods, such as magnetic resonance imaging (MRI), mag- netic resonance angiography (MRA), and ultrasound, posterior circulation ischemic strokes and their underlying mechanisms can be safely and thoroughly investigated. The PCA occupies a critical anatomic position at the end of the posterior circulation and is often the recipient of emboli from either the heart or basilar and vertebral arteries. Although visual field defects are the predominant clinical feature of s-PCAIs, these are frequently associated with visual cognitive disorders. Hitherto, many reports have focused on describing diverse clinico-anatomic correlations $[1,13,20-22,27,28,31,38$, $40]$, but only a few large series $[23,29,36]$ have assessed 
the complete clinico-etiological spectrum of isolated s-PCAIs. We have therefore reviewed the clinical features and etiological patterns of all patients with s-PCAIs included in the Lausanne Stroke Registry (LSR) between 1983 and 1998.

\section{Patients and methods}

From the 3,390 patients consecutively admitted to our populationbased primary care stroke center, we selected those with s-PCAI identified by computed tomography (CT) or MRI. We excluded patients with involvement of the deep territory of the PCA, either isolated or in combination with the superficial territory. The patients' data were encoded in the prospective Lausanne Stroke Registry, the characteristics of which have been described in detail elsewhere [4]. Lesion topography was specified according to templates developed in our own center [37]. The s-PCA included the occipital, inferomedial temporal, and posterior parietal lobes. All patients underwent a standard protocol of investigations, including brain CT with and without contrast (except in patients with known allergy to the contrast medium), extracranial carotid and vertebral Doppler sonography, 12-lead electrocardiography, and standard urine and blood tests. Transcranial Doppler sonography was performed on all patients since 1985 (n: 95). Brain MRI (n: 69), cerebral angiography (MRA: 51, intraarterial: 36), two-dimensional transthoracic (TTE, n: 61) and transesophageal echocardiography (TEE, n: 38), and 24-hour electrocardiography (Holter) monitoring (n: 37) were performed when necessary. All patients underwent detailed neurological and neuropsychological examinations using a standardized French battery of tests, focusing particularly on items such as speech disorders, dyscalculia, apraxia, agnosia, visual color function, visual neglect, spatial orientation, and memory. Vascular risk factors, such as age, sex, hypertension (blood pressure of $>160 / 90 \mathrm{~mm} \mathrm{Hg}$ at least twice before stroke), diabetes mellitus (two or more fasting glucose levels $>7 \mathrm{mmol} / \mathrm{l}$ ), cigarette smoking, hypercholesterolemia (fasting cholesterol levels > $6.5 \mathrm{mmol} / \mathrm{L}$ ), oral contraceptive use, a history of migraine, ischemic heart disease, arrhythmia, or previous transient ischemic attacks (TIAs), were recorded.

Potential causes of infarction were classified according to the following criteria:

1. Cardioembolism: in patients with a potential cardiac embolic source [39].

2. Large artery disease (LAD) with artery-to-artery embolism: $50 \%$ or greater stenosis of the appropriate artery on Doppler ultrasonography, MRA, or conventional angiography, or detection of aortic arch atheromatous plaques by TEE.

3. PCA atherothrombosis.

4. Migraine: in patients developing stroke during a migraine attack.

5. Multiple potential sources of embolism (MPSE): if two or more embolic sources were identified.

6. Uncommon causes: arterial dissection, vasculitis, coagulation disorders, and other rare causes of infarcts.

7. Undetermined etiology: if none of the above causes was identified. The functional outcome at 1 month was assessed using a fivegrade activities of daily living scale (ADL) with grade I as no disability, grade II mild disability (return to all previous activities, but with difficulty), grade III moderate disability (return to main previous activities, but with difficulty), grade IV severe disability (unable to return to most previous activities), and grade $\mathrm{V}$ death as described previously [39].

Statistical significance was estimated using contingency tables and the chi-square test with Yate's correction.

\section{Results}

We identified 117 (3.5\%; 81 men and 36 women) patients with s-PCAI with a mean age of $61.4 \pm 17.1$ years (range of 22-89).

\section{Topography}

Lesions were located in the left hemisphere in 56 cases $(48 \%)$, in the right in $53(45 \%)$, and bilaterally in $8(7 \%)$. Lesion topography is summarized in Fig. 1.

\section{Risk factors}

The distribution of risk factors is summarized in Table 1. Fifteen $(12.8 \%)$ patients had no risk factors.

\section{Presumed causes}

a) Cardioembolism, the most common etiology, was observed in $51(44 \%)$ patients. The echocardiographic

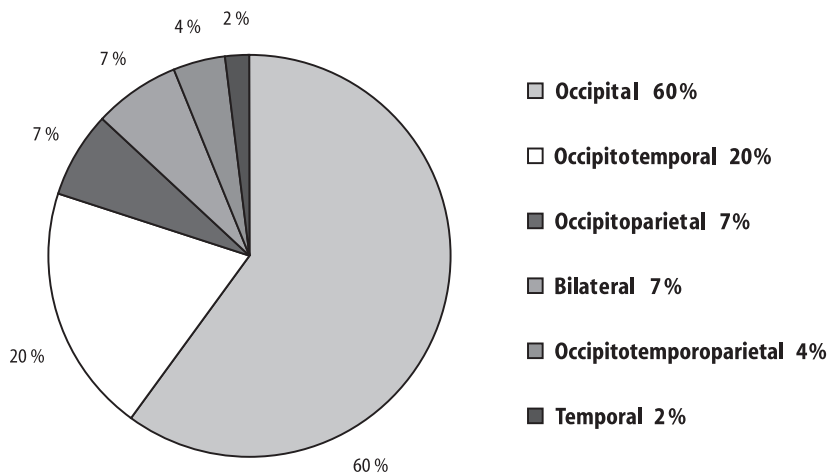

Fig. 1 Topography of infarctions

Table 1 Risk factors in 117 patients with s-PCAI

\begin{tabular}{lc}
\hline Risk factor & $\mathrm{n}=117(\%)$ \\
\hline Hypertension & $46(39.3)$ \\
Diabetes mellitus & $19(16.2)$ \\
Cigarette smoking & $36(30.7)$ \\
Hypercholesterolemia & $29(24.8)$ \\
Oral contraceptive use & $4(3.4)$ \\
Atrial fibrillation & $19(16.2)$ \\
Chronic & $9(7.7)$ \\
Paroxysmal & $10(8.5)$ \\
Coronary disease & $22(18.8)$ \\
Angina pectoris & $11(9.4)$ \\
Myocardial infarction & $9(7.7)$ \\
Congestive heart failure & $2(1.7)$ \\
Migraine & $11(9.4)$ \\
Vascular claudication & $9(7.7)$ \\
\hline
\end{tabular}


findings in these patients are summarized in Table 2a. Two (2\%) patients suffered from sick sinus syndrome, diagnosed after Holter monitoring. Cardioembolism was implicated in 5 out of 7 infarcts with secondary hemorrhagic transformation $(\mathrm{p}<$ $0.05)$ and in 5 out of 8 bilateral infarcts $(\mathrm{p}<0.05)$.

b) LAD with artery-to-artery embolism was the presumed cause in $13(11 \%)$ patients. The details are presented in Table 2b. In one case, left ICA occlusion coexisted with a fetal-type PCA configuration.

c) Local PCA occlusion and stenosis, assessed by conventional angiography or MRA, were each identified separately in two (1.7\%) patients who had neither a cardiac source of embolism nor proximal large artery disease.

d) Migraine was presumed to be the cause of stroke in 4 (3.4\%) patients. Other potential causes of infarction were not found.

e) MPSE: in three (2.5\%) patients, LAD plus a potential cardioembolic source were identified.

f) Rare causes were present in four (3\%) patients; these being isolated central nervous system vasculitis, dissection after chiropractic manipulation diagnosed by MRI and Doppler, venous central thrombosis, and hematological disease with hypercoagulopathy.

g) The cause of stroke was undetermined in 38 (32\%) patients. However, embolism was the most likely etiology in 10, although no embolic source could be detected, even after extensive investigation. In 16 patients, the etiology was not determined, probably as a result of technical limitations during the early days of

Table 2a Echocardiographic features in patients with cardiogenic embolism

\begin{tabular}{ll}
\hline Feature & Number of patients (\%) \\
\hline Segmental left ventricular akinesia & $10(8.5 \%)$ \\
PFO & $13(11 \%)$ \\
$\quad$ With left ventricular akinesia & $1(1 \%)$ \\
Isolated valvular abnormalities & $5(4 \%)$ \\
Myocardial abnormalities with arrhythmia & $9(8 \%)$ \\
Endocarditis & $1(1 \%)$ \\
Atrial thrombus with mitral valve prolapse & $1(1 \%)$ \\
\hline
\end{tabular}

PFO patent foramen ovale; $A S A$ atrial septal defect; $A F$ atrial fibrillation

Table 2b Angiographic and sonographic features in patients with proximal large artery disease

\begin{tabular}{ll}
\hline Feature & $\mathrm{n}=13$ \\
\hline BA disease & 3 \\
Unilateral VA disease & 4 \\
Bilateral VA disease & 1 \\
Tandem pathology (VA and BA disease) & 2 \\
Fetal PCA and ipsilateral ICA occlusion & 1 \\
Aortic arch plaques & 2 \\
\hline
\end{tabular}

$B A$ basilar artery; $V A$ vertebral artery; ICA internal carotid artery the LSR (lack of MRA, MRI, transcranial Doppler, or TEE).

\section{Neurological deficit}

A previous ipsilateral TIA was reported by 20 (17\%) patients. The interval between a TIA and stroke ranged from one day to several months. Clinical features included visual loss on one or both sides, hemianopsia, and/or flashing lights, instability and dizziness, accompanied by a tingling sensation in one or both legs.

The neurological deficit was complete immediately, or within a few minutes, after stroke onset in $97(83 \%)$ patients, progressed smoothly in $13(11 \%)$, and fluctuated in $7(6 \%)$. Headache at stroke onset was reported by $60(51 \%)$ patients, 5 of whom had a history of migraine. It was frontal in $25(21 \%)$, occipital in $6(5 \%)$, diffuse in $6(5 \%)$, above the ipsilateral eye in $10(8.5 \%)$, and hemispheric in $13(11 \%)$.

Visual field defects (summarized in Table 3 ) were the most common clinical sign $(n=112,96 \%)$. Four $(3 \%)$ patients had no visual field abnormalities. In 49 (42\%) patients, visual field defects were the only neurological sign. Sixty-eight $(58 \%)$ patients had higher order visual dysfunction or other neuropsychological deficits; these are summarized in Tables 4 and 5. Visual neglect was associated $(p<0.02)$ with large right PCA territory infarcts, also involving the temporal or parietal lobe. Memory impairment was frequent $(17.5 \%)$ and predominantly associated with left hemisphere lesions $(\mathrm{p}<$ $0.02)$. Language disturbances occurred in $17(14.5 \%)$ patients [global aphasia in $1(1 \%)$, transcortical sensory dysphasia (TSA) in $8(7 \%)$, and amnesic aphasia (AA) in $8(7 \%)$ ]. Prosopagnosia or constructional apraxia ( $\mathrm{p}$ $<0.01)$ or spatial disorientation $(\mathrm{p}<0.05)$ were associated with non-dominant hemisphere or bilateral lesions.

Fourteen (12\%) patients had slight motor deficits (transient in 10) in the absence of any sensory dysfunction. Pure sensory deficits were present in $8(7 \%)$ patients. Of these, $5(4 \%)$ complained of transient paresthesias.

Table 3 Frequency of visual field defects

\begin{tabular}{lc}
\hline Visual field defect & $\mathrm{n}=117(\%)$ \\
\hline Homonymous hemianopia & $78(67)$ \\
Macular sparing & $13(11)$ \\
Quadrantanopia & $26(22)$ \\
Lower & $6(5)$ \\
Upper & $20(17)$ \\
Bilateral deficit & $8(7)$ \\
Cortical blindness & $5(4)$ \\
\hline
\end{tabular}


Table 4 Visual cognitive deficits related to lesioned cerebral hemisphere

\begin{tabular}{lllll}
\hline Deficit & $\begin{array}{l}\text { Right hemisphere } \\
\mathrm{n}=53(\%)\end{array}$ & $\begin{array}{l}\text { Left hemisphere } \\
\mathrm{n}=56(\%)\end{array}$ & $\begin{array}{l}\text { Bilateral } \\
\mathrm{n}=8(\%)\end{array}$ & $\begin{array}{l}\text { Total } \\
\mathrm{n}=117(\%)\end{array}$ \\
\hline Agnosia & $0(0)$ & $7(6)$ & $3(2.5)$ & $10(8.5)$ \\
Prosopagnosia & $4(3)$ & $0(0)$ & $3(2.5)$ & $7(5.5)$ \\
Palinopsia & $2(2)$ & $2(2)$ & $0(0)$ & $4(3)$ \\
Color agnosia & $0(0)$ & $0(0)$ & $4(3)$ & $4(3)$ \\
Color dysnomia & $0(0)$ & $6(5)$ & $0(0)$ & $6(5)$ \\
Visual neglect & $9(8)$ & $2(2)$ & $0(0)$ & $11(9)$ \\
Hallucinations & $5(4)$ & $5(4)$ & $2(2)$ & $12(10)$ \\
$\quad$ Complex & $2(2)$ & $5(4)$ & $2(2)$ & $9(8)$ \\
Elementary & $3(2.5)$ & $0(0)$ & $0(0)$ & $3(2.5)$ \\
\hline
\end{tabular}

Table 5 Neuropsychological deficits related to lesioned cerebral hemisphere

\begin{tabular}{lllll}
\hline Deficit & $\begin{array}{l}\text { Right hemisphere } \\
\mathrm{n} \mathrm{patients} \mathrm{( \% )}\end{array}$ & $\begin{array}{l}\text { Left hemisphere } \\
\mathrm{n} \mathrm{patients} \mathrm{( \% )}\end{array}$ & $\begin{array}{l}\text { Bilateral } \\
\mathrm{n} \text { patients (\%) }\end{array}$ & $\begin{array}{l}\text { Total } \\
\text { n patients (\%) }\end{array}$ \\
\hline Dysphasia & $0(0)$ & $14(12)$ & $3(2.5)$ & $17(14.5)$ \\
Dyslexia & $0(0)$ & $12(10)$ & $3(2.5)$ & $15(13)$ \\
with dysgraphia & $0(0)$ & $4(3)$ & $1(1)$ & $5(4)$ \\
without dysgraphia & $0(0)$ & $8(7)$ & $2(2)$ & $10(9)$ \\
Dyscalculia & $1(1)$ & $5(4)$ & $4(3)$ & $10(9)$ \\
Constructional apraxia & $9(8)$ & $0(0)$ & $2(2)$ & $11(10)$ \\
Ideomotor apraxia & $0(0)$ & $6(5)$ & $2(2)$ & $8(7)$ \\
Agitated confusion & $3(2.5)$ & $5(4)$ & $0(0)$ & $8(7)$ \\
Disorientation & $5(4)$ & $3(2.5)$ & $5(4)$ & $13(11)$ \\
Memory impairment & $2(2)$ & $15(13)$ & $3(2.5)$ & $20(17.5)$ \\
\hline
\end{tabular}

\section{Short-term outcome}

Seventy-five percent of the patients had either no functional disability or only minor sequelae which did not compromise their return to previous activities. Twentythree $(20 \%)$ recovered partially, while only $6(5 \%)$ were severely disabled. No deaths occurred.

\section{Discussion}

To the best of our knowledge, only a few clinical studies $[23,29,36]$ have focused on the underlying etiology of s-PCAI. The existing large series which have studied posterior circulation infarction have often combined deep and superficial involvement. In our series, s-PCAIs accounted for $3.5 \%$ of all strokes in our registry, in agreement with the rate of $4.2 \%$ reported by Milandre et al. [23]. The occipital lobe, the most common cortical PCA territory involved [7], was affected in $97 \%$ of cases, with isolated occipital lobe involvement being seen in $60 \%$. The posterior temporal and parietal lobes were implicated in $27 \%$ and $12 \%$ of patients, respectively, as previously suggested by Yamamoto et al. [42].

When all embolic sources (cardiac, aortic arch, vertebrobasilar) were taken together, embolism was the most common mechanism of stroke, accounting for at least $58 \%$ of cases. It was the most likely cause in one-third of indeterminate etiology infarcts, even though no source could be detected. The estimated cumulative rate of em- bolism would most probably be $66 \%$. Our results agree with those of previous studies reporting rates of embolism ranging from $57 \%$ [36] to $77 \%$ [29]. Heart disease, especially atrial fibrillation (AF), was the most important source of emboli (44\%) and responsible for the majority of hemorrhagic or bilateral infarcts.

Several authors have emphasized the importance of artery-to-artery embolism (AAE) as a cause of PCAIs, with the vertebrobasilar axis being considered to be the major donor site $[8,9,12,16,26,32,42]$ On the basis of angiographic and echocardiographic findings, Moryasu [25] reported an $11 \%$ rate of AEE. Based on angiographic criteria, Brandt [6] identified embolism from a vertebrobasilar source in $17 \%$ of patients. Rates of vertebrobasilar LAD of up to $19 \%$ have been reported [36]. In Castaigne's post-mortem study [10], AAE from vertebrobasilar atherosclerotic stenosis accounted for $50 \%$ of PCAIs. The relatively low frequency $(12 \%)$ of AAE in our study could be partly explained by the facts that:

a) cerebral angiography was not performed on all patients and $b$ ) the majority of the aforementioned series did not include exclusively s-PCAI. Moreover, our personal experience is that the interpretation of Doppler sonography and magnetic resonance angiography in proximal vertebral artery disease can vary considerably. Yamamoto et al. [42] have suggested that AAE tends to produce infarcts involving the PCA in combination with other posterior circulation territories (brainstem and cerebellum), while infarcts caused by cardiac embolism 
and intrinsic PCA disease usually produce pure PCA infarcts.

One (22\%) or both (7\%) PCAs may arise from the ipsilateral ICAs [12]. Infarction attributed to embolism from the ICA through a fetal PCA configuration is rare, even in large series $[19,23,30,36]$. We here report a single patient $(0.8 \%)$. Aortic atheroma was identified as a potential emboligenic source in two patients (combined with potential cardiogenic embolism in one). Its significance as a source of embolism to the posterior circulation is unknown, since the aorta is not always systematically studied, even when TEE is performed.

On the basis of intra-arterial and MR angiography, it is often difficult to differentiate embolic from atherosclerotic PCA occlusion; however, in the absence of an emboligenic source, in situ disease is strongly suspected. The two conditions cannot be reliably distinguished by clinical features. In our series, local occlusion and stenosis of the PCA were infrequent ( $1.7 \%$ each), as in previous reports 29,36].

Among rare causes, vertebral artery dissection (VAD) was diagnosed by MRA in only one patient.

The frequency of an undetermined etiology in recent large studies ranges from $11 \%$ to $32 \%[6,23,25,33,36]$, in agreement with our results (32\%).

Although Fisher [12] mentioned that the PCA is "the artery of migraine par excellence", the relationship between migraine and posterior circulation ischemia is controversial. In published series, migrainous infarct rates range from 0 to $20 \%[6,20,23,29,36]$. The pathogenesis of migraine-related stroke remains obscure, although various mechanisms (vasospasm, platelet dysfunction, and hypoperfusion secondary to spreading depression) have been evoked. Nevertheless, pathologic changes were not reported in autopsied cases [41]. Migraine patients may be particularly susceptible to stroke-associated headache, simply reflecting the more frequent occurrence of cephalalgia in vertebrobasilar compared to anterior circulation ischemia $[17,18,24]$.

PCAIs without associated visual symptoms are quite rare [7]. Poor collateral circulation in the inferior striate cortex may explain its vulnerability to infarction [15] and thus the discrepancy between the frequency of inferior and superior quadrantanopsia in our and other studies $[5,23,33,42]$. The frequency of macular sparing varies widely between different series [5]. Inter-individual differences in the pattern of occipital pole blood supply and the lack of perimetry testing in all patients may account for discrepancies in the rate of macular sparing.

Motor deficits accompanying PCA infarction are infrequent and hard to interpret. They may be with thalamocapsular infarct or cerebral peduncle involvement [5]. However, motor deficits were observed in $19 \%$ of our patients (transient or minor in most), although no lesion other than s-PCAI was demonstrated by CT or MRI. In accordance with our results, Johansson et al. [14] described hemiparesis without brainstem symptoms in $24 \%$ of CT-identified occipital infarcts, suggesting involvement of the PCA perforating branches. Steinke et al. [36] reported motor weakness in $20 \%$ of s-PCAIs. According to Zeal and Rhoton [43], direct PCA perforating branches often arise from the P2 segment, indicating a possible association between cortical infarction and hypoperfusion of the posterior internal capsule.

Sensory deficits in PCA infarcts, generally resulting from lateral thalamic involvement, occur more frequently than motor deficits [9]. In our series, however, as in that of Steinke et al. [36], only $14 \%$ of patients reported sensory symptoms. Comparison with other large series is difficult owing to population heterogeneity. Brandt et al. [5] have suggested that the frequency of combined thalamic and s-PCA infarctions has been largely underestimated by CT-based studies, and thalamic involvement is to be expected in $20-30 \%$ of cases.

To our knowledge, only a few large series have estimated the frequency of neuropsychological deficits and higher order visual dysfunction encountered in PCA infarction, with results ranging from 32 to $46-50 \%[6,23$, 36].

Visual agnosia (VAg) usually implies left large or bilateral lesions [2]. In our study, VAg resulting from the former was accompanied by color dysnomia and alexia without dysgraphia in 6 out of 7 patients. VAg resulting from bilateral lesions was always accompanied by color agnosia when the lower banks of the calcarine fissures were mainly involved. Prosopagnosia is described as a rare and unusual finding [27]. Although most autopsy studies demonstrated bilateral involvement [22], we observed that right inferior occipitotemporal lesions are sufficient for prosopagnosia to occur. A bilateral lesion invariably resulted in prosopagnosia associated with color agnosia. Visual perseverations were invariably associated with lesions of either occipitoparietal junction. Visual neglect was usually absent when infarction was limited to the occipital lobe. In $80 \%$ of patients with visual neglect, a right occipital lesion extending to the parietal or temporal lobe was detected. Visual hallucinations, a well known phenomenon of PCA infarction [12], were frequently seen if systematically searched for. In contrast to our findings, some authors $[12,38]$ have suggested that complex hallucinations are preferentially associated with right hemisphere lesions.

Alexia without agraphia, an important and specific syndrome associated with left PCA infarction, has been reported at rates ranging from $6-16 \%[23,33]$. In our series, color dysnomia, when observed, was always associated with alexia without agraphia. All patients presenting alexia with agraphia also had a certain degree of anomia; this combination invariably resulted from a lesion involving the left parietotemporal junction. Although infrequent, dysphasia (mainly TSA and AA) occurring with left PCA territory infarction is well 
documented $[9,23]$, and was observed in $14 \%$ of the patients in our study. Rates approximating $11 \%$ have been reported $[23,35]$. We were not able to attribute a localizing significance to each type of aphasia; however, we observed that TSA was associated with larger lesions.

Memory impairment, usually resulting from left or bilateral lesions $[3,12,34]$, is not uncommon ranging from 11 to $55 \%[6,23,29,33,36]$. It was associated with left inferomedial temporal involvement in 15 out of 20 of our patients. In $85 \%$ of our cases, it manifested as mild to moderate difficulty in learning verbally presented material, which was accompanied by a relatively fair performance in recalling complex visual material as long as the right hemisphere was spared. An agitated confusional state (ACS), though usually related to bilateral or left hemispheral infarcts [12], was not specifically associated in our series with either of the above locations, in accordance with the results of Milandre et al. [23]. The rather low incidence of ACS in our study (7\%), as already suggested [11], could be attributed to differences in lesion size, topography, premorbid psychological and organic factors, and interpretation of visual hallucinations. Furthermore, we preferred to describe patients who were non-agitated, but disoriented in terms of time and/or place, as a distinct subgroup. Although reported in $35 \%$ of cases by Steinke et al. [36], spatial disorientation was prominent in only $10(8 \%)$ right or bilateral occipitoparietal infarcts. Left hemisphere lesions resulted in a rather global disorientation involving time, place, and space.

In conclusion, our findings suggest that s-PCAIs:

a) are uncommon, representing $3.5 \%$ of all strokes and less than a third of all PCA infarctions.

b) although associated with embolism in 3 out of 5 patients, documentation of the emboligenic source is often not feasible, hence its ultimate contribution to $\mathrm{s}$-PCA ischemia remains speculative.

c) if meticulously searched for, neuropsychological deficits accompany the classical visual field manifestations in almost $60 \%$ of patients. Visual field manifestations constituted the unique manifestation of sPCAI in 2 out of 5 patients.

\section{References}

1. Aldrich MS, Alessi AG, Beck RW, Gilman S (1987) Cortical blindness: etiology, diagnosis, and prognosis. Ann Neurol 21:149-158

2. Alexander MF, Albert ML (1983) The anatomical basis of visual agnosia. In: Kertesz A (ed) Localization in Neuropsychology. New York, Academic Press, pp 393-415

3. Benson DF, Marsden CD, Meadows JC (1974) The amnesic syndrome of posterior cerebral artery occlusion. Acta Neurol Scandinav 50:133-145

4. Bogousslavsky J, Van Melle G, Regli F (1988) The Lausanne Stroke Registry: Analysis of 1000 consecutive patients with first stroke. Neurology 19: 1083-1092

5. Brandt T, Steinke W, Thie A, Pessin MS, Caplan LR (2000) Posterior cerebral artery territory infarcts: clinical features, infarct topography, causes and outcome. Cerebrovasc Dis 10:170-182

6. Brandt T, Thie A, Caplan LR, Hacke W (1995) Infarkte in Versorgungsgebiet der A. cerebri posterior. Nervenarzt 66:267-274

7. Caplan LR (1995) Posterior Cerebral Artery. In: Bogousslavsky J, Caplan LR (eds) Stroke syndromes. New York, Cambridge University Press, pp 290-299

8. Caplan LR, Amarenco P, Rosengart A, Lafranchise EF, Teal PA, et al. (1992) Embolism from vertebral artery origin occlusive disease. Neurology 42 : 1505-1512
9. Caplan LR, Bogousslavsky J (1998) Posterior cerebral artery syndromes. In: Ginsberg MD, Bogousslavsky J (eds) Cerebrovascular disease: pathophysiology, diagnosis, and management. Boston, Blackwell, pp 1028-1045

10. Castaigne P, Lhermitte F, Gautier JC, Escourolle R, Derouesne C, et al. (1973) Arterial occlusion in the vertebro-basilar system: A study of 44 patients with post-mortem data. Brain 96:133-154

11. Devinsky O, Bear D, Volpe BT (1988) Confusional states following posterior cerebral artery infarction. Arch Neurol 45:160-163

12. Fisher CM (1986) The posterior cerebral artery syndrome. Can J Neurol Sci 13:232-239

13. Henderson VW, Friedman RB, Teng EL, Weiner JM (1985) Left hemisphere pathways in reading: interferences from pure alexia without hemianopia. Neurology 35:962-968

14. Johansson T (1985) Occipital Infarctions associated with hemiparesis. Eur Neurol 24:276-280

15. Kitajima M, Korogi Y, Kido T, Ikeda O, Morishita S, et al. (1998) MRI in occipital lobe infarcts: classification by involvement of the striate cortex. Neuroradiology 40:710-715

16. Koroshetz WJ, Ropper AH (1987) Artery-to-artery embolism causing stroke in the posterior circulation. Neurology 37:292-296
17. Koudstaal PJ, Van Gijn J, Kappelle LJ (1991) TIA Study Group. Headache in transient or permanent cerebral ischemia. Stroke 22:754-759

18. Kumral E, Bogousslavsky J, Van Melle G, Regli F, Pierre P (1995) Headache at stroke onset: the Lausanne Stroke Registry. J Neurol Neurosurg Psychiatry 58:490-492

19. Linn FH, Chang HM, Caplan LR (1997) Carotid artery disease: a rare cause of posterior cerebral artery territory infarction. J Neurovasc Dis 2:31-34

20. Mc Auley DL, Ross Russel RW (1979) Correlation of CAT scan and visual field defects in vascular lesions of the posterior visual pathways. J Neurol Neurosurg Psychiatry 42:298-311

21. Meadows JC, Munro SF (1977) Palinopsia. J Neurol Neurosurg Psychiatry $40: 5-8$

22. Meadows JC (1974) The anatomical basis of prosopagnosia. Journal of Neurology, Neurosurg Psychiatry 37: 489-501

23. Milandre L, Brosset C, Botti G, Khalil R (1994) Etude de 82 infarctus du territoire des artères cérébrales postérieures. Rev Neurol (Paris) 150: 133-141

24. Moen M, Levine SR, Newman DS, DullBaird A, Brown GG, et al. (1988) Bilateral Posterior Cerebral Artery Stroke in a Young Migraine Sufferer. Stroke 19:525-528 
25. Moriyasu $\mathrm{H}$, Yasaka M, Minematsu K, Oita J, Yamaguchi T (1995) The pathogenesis of brain infarction in the posterior cerebral artery territory. Rinsho Shinkeigaku 35:344-351

26. Muller-Kuppers M, Graf KJ, Pessin MS, DeWitt LD, Caplan LR (1997) Intracranial vertebral artery disease in the New England Medical Center Posterior Circulation Registry. Eur Neurol 37: 146-156

27. Nardelli E, Buonanno F, Coccia G, Fiaschi A, Terzian H, et al. (1982) Prosopagnosia. Eur Neurol 21:289-297

28. Peroutka SJ, Sohmer BH, Kumar AJ, Folstein M, Robinson RG (1982) Hallucinations and delusions following a right temporoparietooccipital infarction. Johns Hopkins Med J 151:181-185

29. Pessin MS, Lathi ES, Cohen MB, Kwan ES, Hedges TR, Caplan LR (1987) Clinical features and mechanisms of occipital infarction. Ann Neurol 21:290-299

30. Pessin MS, Kwan ES, Scott RM, Hedges TR III (1989) Occipital infarction with hemianopsia from carotid occlusive disease. Stroke 20:409-411

31. Pillon B, Bakchine S, Lhermitte F (1987) Alexia without agraphia in a left-handed patient with a right occipital lesion. Arch Neurol 44:1257-1262
32. Schwarz S, Egelhof T, Schwab S, Hacke W (1997) Basilar artery embolism: clinical syndrome and neuroradiologic patterns in patients without permanent occlusion of the basilar artery. Neurology 49:1346-1352

33. Servan J, Catala M, Rancurel G (1992) Posterior cerebral artery (PCA) infarction: a study of 76 cases. Cerebrovasc Dis 4:233

34. Servan J, Verstichel P, Catala M, Rancurel G (1994) Syndrome amnesique et fabulations au cours d'infarctus du territoire de l'artère cérébrale postérieure. Rev Neurol (Paris) 150: 201-208

35. Servan J, Verstichel P, Catala M, Yakovleff A, Rancurel G (1995) Aphasia and infarction of the posterior cerebral artery territory. J Neurol 242:87-92

36. Steinke W, Mangold J, Schwartz A, Hennerici M (1997) Mechanisms of infarction in the superficial posterior cerebral artery territory. J Neurol 244: 571-578

37. Tatu L, Moulin T, Bogousslavsky J, Duvernoy H (1998) Arterial territories of the human brain: Cerebral Hemispheres. Neurology 50:1699-1708
38. Tohgi $\mathrm{H}$, Watanabe $\mathrm{K}$, Takahashi $\mathrm{H}$, Yonezawa H, Hatano K, et al. (1994) Prosopagnosia without topographagnosia and object agnosia associated with a lesion confined to the right occipitotemporal region. J Neurol 241:470-474

39. Vauthey C, de Freitas G R, Van Melle G, Devuyst G, Bogousslavsky J (2000) Better outcome after stroke with higher serum cholesterol levels. Neurology 54:1944-1948

40. Von cramon DY, Hebel N, Schuri U (1988) Verbal Memory and Learning in Unilateral Posterior Cerebral Infarction. Brain 111:1061-1077

41. Welch KMA, Tatemichi TK, Mohr JP (1998) Migraine and Stroke. In: Barnett HJM, Mohr JP, Stein BM, Yatsu FM (eds) Stroke: Pathophysiology, Diagnosis and Management. New York, Churchill Livingstone, pp 845-863

42. Yamamoto Y, Georgiadis AL, Chang HM, Caplan LR (1999) Posterior cerebral artery territory infarcts in the New England Medical Center Posterior Circulation Registry. Arch Neurol 56:824-832

43. Zeal AA, Rhoton AL Jr (1978) Microsurgical anatomy of the posterior cerebral artery. J Neurosurg 48:354-359 